研 究

\title{
金型潤滑技術の定量的評価と新潤滑剂の開発について
}

 \\ ${ }^{21}$ 日産自動車侏パワートレイン技術開発試作部，テ230-0053 横浜市鶴見区大黒町 6-1. \\ 衴日産自動車(侏)成形技術部，干220-8023 横浜市神奈川区宝町 2 .

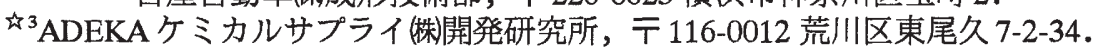

\section{Quantative Analysis of Die Wall Lubrication and New Lubricant Development}

 \\ ${ }^{2} 1$ Powertrain Technologies and Prototype Development Department Nissan Motor Co.,Ltd., \\ 6-1 Daikoku-cho, Tsurumi-ku, Yokohama 230-0023, Japan. \\ ${ }^{2}$ Material Process Engineering Department Nissan Motor Co.,Ltd., 2 Takara-cho, Kanagawa-ku, Yokohama 220-8023, Japan. \\ ${ }^{2}{ }^{3}$ R\&D Division of ADEKA CHEMICAL SUPPLY CORPORATION, 7-2-34 Higashiogu, Arakawa-ku, Tokyo 116-0012, Japan.
}

Received May 12, 2006

\section{SYNOPSIS}

Recently several new technologies are introduced to achieve high density of PM such as warm compaction, surface densification, high velocity compaction and so on. Die wall lubrication is one of these technologies. However, the study of quantitative analysis of die wall lubrication is very few, neither the suitable lubricant for die wall lubrication. The authors studied the die wall lubrication technologies itself comparing TRIBO type and CORONA spark type and also studied several lubricant electric charge value. Trough these studies, the new lubricant for die wall lubrication is synthesized.

KEYWORDS

die wall lubrication, warm compaction, high density, high strength, quantative analysis

\section{1 まえがき}

現在鉄系焼結機械部品の大部分は自動車に使われている. 近年自動車は特に環境への配慮等から, 燃費向上が強く要請 され，部品の小型軽量化が進んでいる。このため単位面積に かかる負荷が大きくなって来ることから, 焼結部品のより高 密度化が要求されてきており,これに対応するために, 著者ら

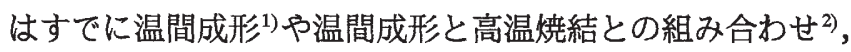

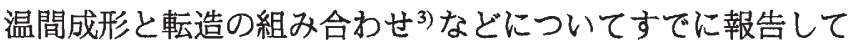
来ている. 最近では高密度手法として, 金型潤滑の検討も盛 んになってきている ${ }^{4,5}$.この方法は構造部材だけでなく, 最 近脚光を浴びている圧粉軟磁性材等にも応用が効くため大き な可能性を秘めた技術といえる. しかしながら, 定量的な研 究は殆んどされていないのが実情である.今回我々は金型潤 滑の定量的な検討を行い，新潤滑郕を開発した。今回はその 経緯について記述する。

\section{2 開発の背景と開発の目標}

今回の開発状況を述べる金型潤滑の状況について, 開発の 前提を確認する. 通常の内部潤滑(原料粉へ潤滑剂を添加)の
場合は原料混合粉に対して $0.6 \sim 0.8$ mass\% (以下本論文で特 に断りが無い場合は％=mass\% とする) を添加する場合が多 く, 金型潤滑ではこの内部潤滑の添加量を $0.1 \sim 0.2 \%$ にて, 粉末の圧縮性を向上させて, 潤滑の足りない部分を外部潤滑 で補う工法である。粉末成形においては，粉末同士の摩擦低 下の必要もあるので，金型潤滑といえども内部潤滑剤を $0 に$ することは現実的ではなく, 前述のように $0.1 〜 0.2 \%$ の内部 润滑を含むのが一般的である.また，金型潤滑の場合は金型 の “かじり”(金型の異常摩耗，凝着)を防止する効果もある ので, 必ずしも高密度部品狙いでなくて, 複雑形状部品成形 の場合の金型のかじり防止に用いても良いわけである.この ため今回の開発の目標としては,密度は $7.3 \mathrm{Mg} / \mathrm{m}^{3}$ を超えるこ と，潤滑剂の塗布量バラッキは, $3 \sigma=0.1$ 以下であり，従来 の0.6\%の内部添加潤滑剂の成形と同等以下の抜き出し圧力を 狙うこととした。

3 試料および実験方法

3.1 金型潤滑システムの選定

まず各種の金型潤滑方法についてその得失を紙上で比較検 
討した.検討した方法は刷毛による塗布, 液体系のスプレー， 静電塗装によるもののうち, 静電気発生機構として, 摩擦夕 イプ(TRIBO方式)のものとコロナ放電タイプのものである.

Table 1にこれらの方法の得失表を示した.この表からわか るようにコロナ放電による方法が全体的に優位といえる。し かしながらコロナ放電タイプは静電ガンが大きく,プレスの 粉末供給箱(フィーダーボックス)の近傍に取り付けることが 難しく，自動化に大きな障害があるといえる，このため，粉 末付着力の安定性はコロナ放電タイプよりやや落ちるが, 装 置の簡便なTRIBO方式を採用し, 潤滑剤の改良で付着力を安 定させることとした。

\section{2 粉末供給装置の選定}

次に蕳滑剤の粉末の供給装置について検討した.これにつ いてはFig.1に示す従来のタイプと新たに選定したタイプにつ いて見当した。従来タイプでは潤滑剂は空気により浮遊タン ク内で浮遊しており，これに空気圧をかけて，噴射ガンから 潤滑剤金型に投射するわけである.新タイプはスクリューコ ンベヤーで粉末を定量的に切り出し, 空気圧にて静電ガンに 送るものである.これらの粉末について従来から使用されて いる潤滑剤として樹脂系の $\mathrm{A}$ 社の $\mathrm{A}$ 粉，およびワックス(ア ミド)系のB 社の B 粉末について, 各装置を用いた場合のば らつきを表に示した.この表からわかるように新装置の方が

Table 1 Advantages and disadvantages of several die wall lubrication technologies.

\begin{tabular}{|c|c|c|c|c|c|c|c|c|}
\hline \multicolumn{2}{|c|}{ Method } & Lubricant & Cost & Automation & $\begin{array}{l}\text { Complex } \\
\text { shape forming }\end{array}$ & Stability & $\begin{array}{l}\text { Lubrication } \\
\text { ability }\end{array}$ & $\begin{array}{l}\text { Cold } \\
\text { Compaction }\end{array}$ \\
\hline \multicolumn{2}{|c|}{ Brushing } & $\begin{array}{l}\text { Liquid or } \\
\text { Powder }\end{array}$ & High & $\begin{array}{c}\text { Difficult } \\
\text { (Long cycle time) }\end{array}$ & (2) & $\underset{\text { (uneven) }}{X}$ & $\begin{array}{l}\text { NO } \\
\text { Detail data }\end{array}$ & 0 \\
\hline \multicolumn{2}{|c|}{ Spray } & Liquid & Medium & $\begin{array}{c}\text { Difficult } \\
\text { a little bit } \\
\text { (Evaporation) }\end{array}$ & $\triangle_{\text {(One Direction) }}$ & $\begin{array}{c}\text { (O) } \\
\text { (Only with warm } \\
\text { compaction) }\end{array}$ & $\begin{array}{l}\text { TOYOTA } \\
\text { Reported }\end{array}$ & $\underset{\text { (Water solvent) }}{\mathrm{X}}$ \\
\hline \multirow{2}{*}{$\begin{array}{l}\text { Electric } \\
\text { Charging } \\
\text { method }\end{array}$} & $\begin{array}{l}\text { TORIBO } \\
\text { (FRICTION) }\end{array}$ & Powder & Medium & Easy & (a) & $\underset{\substack{\text { Low } \\
\text { adhesion) }}}{\triangle}$ & $\begin{array}{l}\text { NO } \\
\text { Detail data }\end{array}$ & (a) \\
\hline & $\begin{array}{l}\text { CORONA } \\
\text { SPARK }\end{array}$ & Powder & Medium & $\begin{array}{c}\text { Difficult } \\
\text { a little bit } \\
\text { (Electrode space }\end{array}$ & (2) & 0 & $\begin{array}{l}\text { NO } \\
\text { Detail data }\end{array}$ & (C) \\
\hline
\end{tabular}

\begin{tabular}{|c|c|c|}
\hline \multirow{2}{*}{} & \multicolumn{2}{|c|}{ Weight scatter $\sigma(\mathrm{g})$} \\
\cline { 2 - 3 } & Lubricant A & Lubricant B \\
\hline Conventional & 0.053 & 0.043 \\
\hline New & $0.026(\mathbf{\Delta} 50 \%)$ & $0.010(\mathbf{\Delta} 77 \%)$ \\
\hline
\end{tabular}

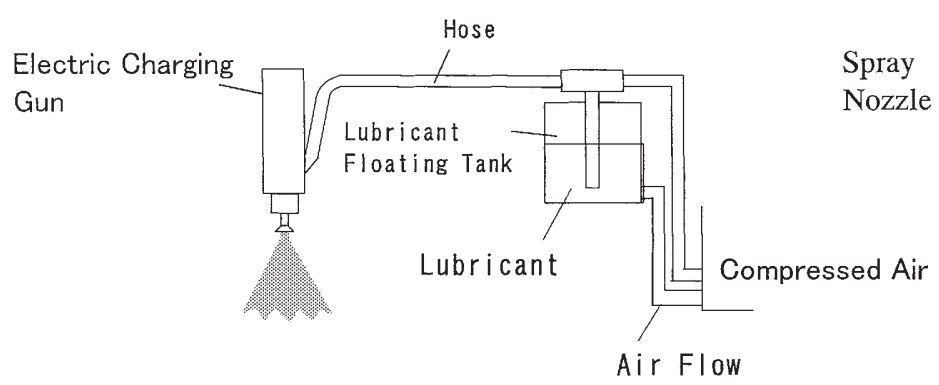

Conventional Apparatus

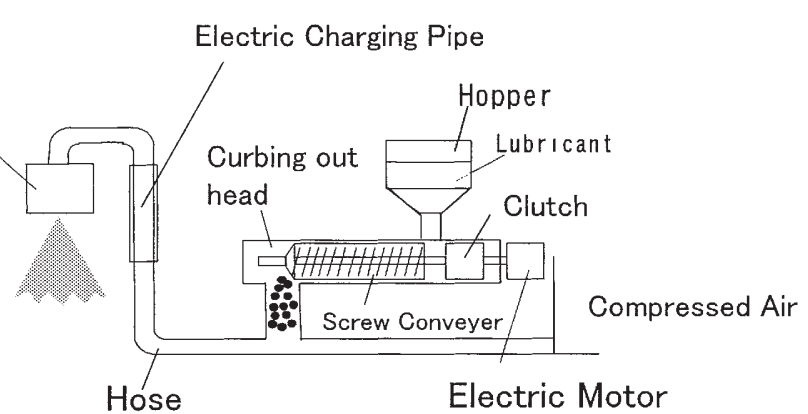

New Apparatus (Made by ASAHI SANACK)

Characteristics:Constant weight of lubricants are curbed out by force with screw conveyer

Lubrication condition is not varied by atmosphere, etc

Lubricants are sprayed by air-brush system

Lubrication condition is varied by flow ability and moisture

Fig.1 Diagram of conventional and new die wall lubrication appratus. 
従来の装置に比べてどちらの粉末を用いてもばらつきが小さ いことがわかる。

以上の予備検討から静電方式(TORIBO)に粉末定量供給装置 を付けた実験装置で潤滑剤の開発を行うこととした。

3.3 金型潤滑の定量評価と金型潤滑用新潤滑剤の開発

Table 2に今回の定量評価に用いた䦭滑剤の一覧表を示す, この中で開発材は EBS, 脂肪酸アミド誘導体とステアリン酸 リチウムの溶融湿合系である. Fig.2に電位測定器の概要を示 す.これは基本的にはファラデーゲージと呼ばれるタイプの 電位測定器であり, 絶縁したカップに各潤滑剤を前記の浲布 装置で塗布し，その潤滑剤の電位を測るものである．次に Fig.3に潤滑剤の付着力を測定する方法の概要を示す.これは 比較的簡便な方法であり, 前記のファラデーゲージ中のカッ プに潤滑剤を塗布後,一定の高さから落下させて，その前後 で付着潤滑凨の重量を測定するものである. 次に実際のスプ ロケット形状を用いた成形後の抜き出し力測定の実験方法に ついて説明する.これは 26 歯の外径 $50 \mathrm{~mm}$ 内径 $10 \mathrm{~mm}$ のサ イレントチェーンスプロケットを成形し，その抜き出し力を 測定するものである. 原料鉄粉は神戸製鋼の $300 \mathrm{NH}$ に $2 \% \mathrm{Cu}$, $0.8 \%$ Cを添加し, 内部潤滑剂として $0.1 \%$ の潤滑剂を加えたも のである. 実験時の気温は $290 \mathrm{~K}\left(17^{\circ} \mathrm{C}\right)$, 湿度は $31 \%$ 成形圧

Table 2 List of examined lubricants.

\begin{tabular}{|c|c|l|l|}
\hline Supplier & Name & \multicolumn{1}{|c|}{ Type } & Particulate Size \\
\hline $\mathrm{A}$ & $\mathrm{A} 1$ & Artificial reign & 0.05 \\
\hline $\mathrm{B}$ & $\mathrm{B} 1$ & Wax(Amide) & 0.5 \\
\hline \multirow{3}{*}{$\begin{array}{l}\text { ADENKA } \\
\text { CHEMICAL } \\
\text { SUPPLY } \\
\text { CO }\end{array}$} & $\mathrm{B} 2$ & Lithium stearate & 0.01 \\
\cline { 2 - 4 } & $\mathrm{Y} 1$ & EBS & 0.025 \\
\cline { 2 - 4 } & $\mathrm{Y} 2$ & Zinc stearate & 0.0189 \\
\cline { 2 - 4 } & Developed & $\begin{array}{l}\text { EBS+ } \\
\text { Fatty amide derivative+ } \\
\text { Lithium stearate }\end{array}$ & 0.0131 \\
\hline
\end{tabular}

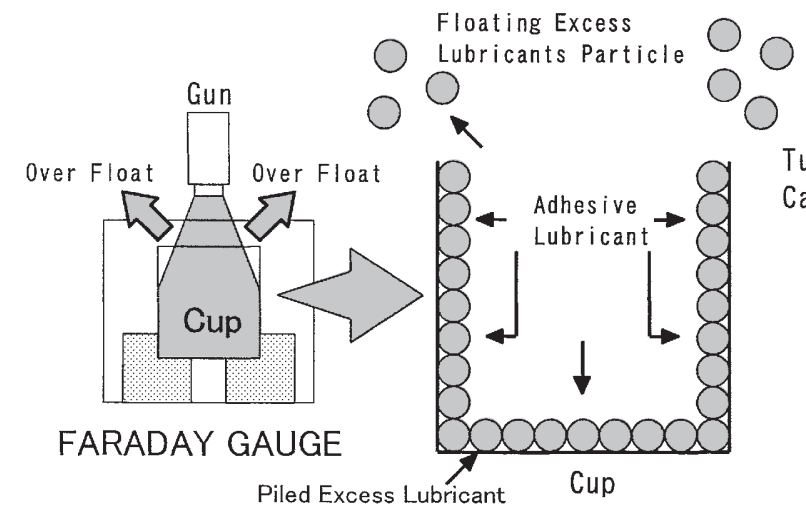

力は $490 \mathrm{MPa}\left(5\right.$ tonf $\left./ \mathrm{cm}^{2}\right)$ で狙い密度は $7.35 \mathrm{Mg} / \mathrm{m}^{3}$ とした.プ レスはヨシズカの総トン数 200 トンのCNCプレスを用い. 金 型は $283 \mathrm{~K}\left(120^{\circ} \mathrm{C}\right)$, 鉄粉は $288 \mathrm{~K}\left(125^{\circ} \mathrm{C}\right)$ とした。

\section{4 量産性を考虑した試作実験}

最後に量産性を確認するために, 外径 $30 \mathrm{~mm}$ 厚さ $9.5 \mathrm{~mm}$ の 円盤上のブランク部品の連続成形の実験を行った. 原料鉄粉 は金型閵滑用鉄粉としては神戸製鋼の $300 \mathrm{MH} 2 \% \mathrm{Cu}, 0.8 \% \mathrm{C}$ を添加し，内部潤滑剤として $0.1 \%$ の潤滑剤を加えたものであ る．比較用としての内部潤滑粉末としては，神戸製鋼の $300 \mathrm{MH}$ に $2 \% \mathrm{Cu}, 0.8 \% \mathrm{C}$ を添加し，内部潤滑剂として $0.6 \%$ の 潤滑剤を加えたものである.実験時の気温は $288 \mathrm{~K}\left(15^{\circ} \mathrm{C}\right)$, 湿 度は $35 \%$, 成形圧力は $686 \mathrm{MPa}$ (7 tonf $/ \mathrm{cm}^{2}$ 成形速度は 9ケ 160 秒，潤滑剂の投射量は $0.04 \mathrm{~g}$ ，狙い密度は $7.35 \mathrm{Mg} / \mathrm{m}^{3}$ とした。 プレスはヨシズカの総トン数 100 トンのメカプレスを用い。 金型，鉄粉共に $293 \mathrm{~K}\left(130^{\circ} \mathrm{C}\right)$ とした。

\section{4 実験結果と考察}

Fig.4に各潤滑剤の電位量を示す.開発材の電位量が一番高 く次が従来材中のA1粉である.ついで従来材のB1粉であり， その他はすべてこれらよりかなり低い值である.開発材の電 位量が一番高いのは,この材料が他と全く異なる結晶構造を

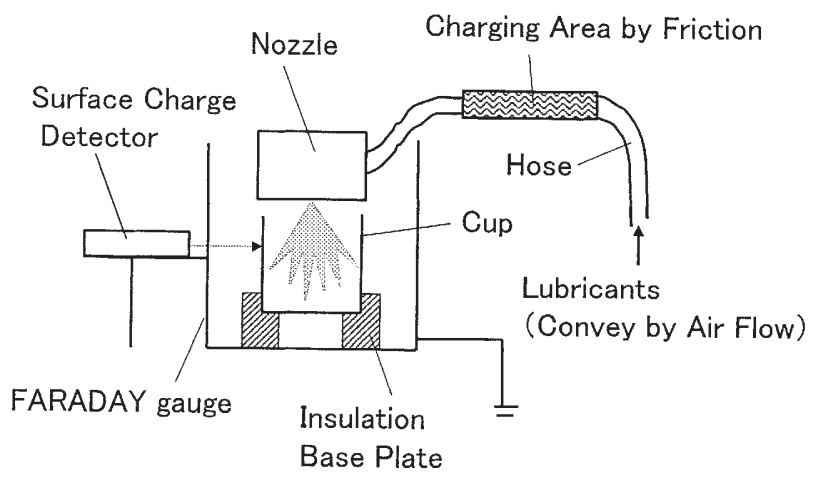

Fig.2 Lubricant spray gun and FARADAY gauge.
Turn-over and

Cap Drop Shock Test

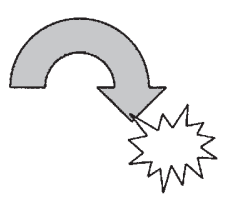

With Low Charged Value

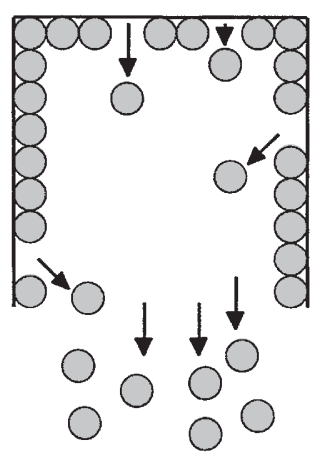

Drop Lubricant of Excess or Low Adhesive Strength

Fig.3 Measurement method of adhesive strength. 




Fig.4 Electricc harged value (V) of examined lubricants.

とるためと考えられるが, 詳細については今後さらに検討し たい.Fig.5に開発材と従来材の $\mathrm{A} 1$ 粉の投射量と付着量の関 係について示した。この図から判るように $\mathrm{A} 1$ 粉では投射量 の8割程度しか付着していないのに対して, 開発材は投射量 の殆んどが付着したままである.

Fig.6に前項3.3で実験したスプロケット形状の成形の場合 の各潤滑剤およびシステムと抜き出し力の関係について示し た. 金型潤滑を行うと, 型潤滑無しに比べてかなり拔き出し 力は下がる. 但し $\mathrm{A} 1$ 粉の $0.02 \mathrm{~g}$ 投射では殆んど効果がない.

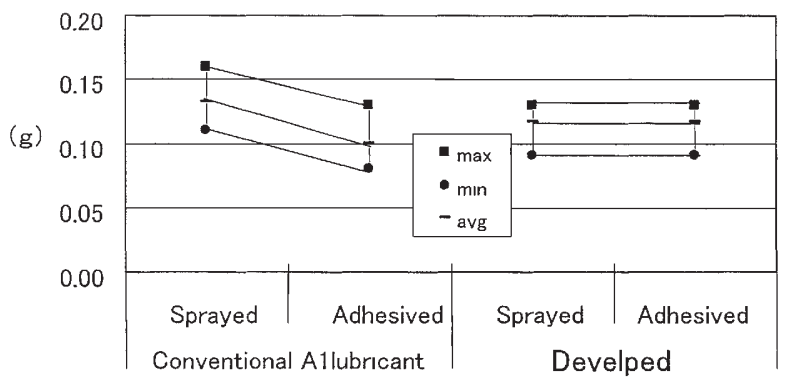

Fig.5 Sprayed and adhesived lubricant in the examination.
開発材の場合は従来材に比べて抜き出し力が低下する.投射 量が多い程拔き出し力は低下する.今回詳細な記述は割愛す るが, 従来の潤滑剤で $0.2,0.5 \mathrm{~g}$ と 2 水準でさらに量を増やし て実験したが $0.5 \mathrm{~g}$ では潤滑棛が㠜集し，潤滑特性も良くない このため今回程度の大きさの部品であれば, 投射量の上限は $0.2 \mathrm{~g}$ 程度であり，0.1gでも十分といえる.

Fig.7 に前項 3.4 で実験した連続 100 ケ成形試作における各 種潤滑の場合の抜き出し圧力について示す.この図から判る

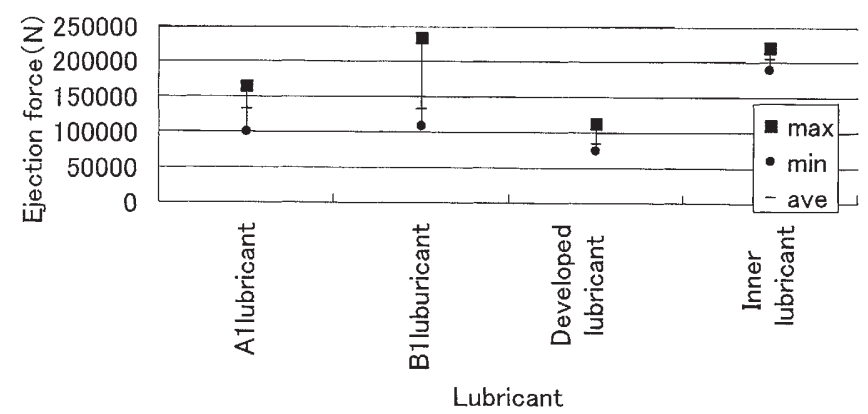

Fig.7 Ejection force under the several conditions (hockey-pack shape, $\mathrm{n}=100$ ).



Fig.6 Ejection force under the several conditions (sprocket shape). 


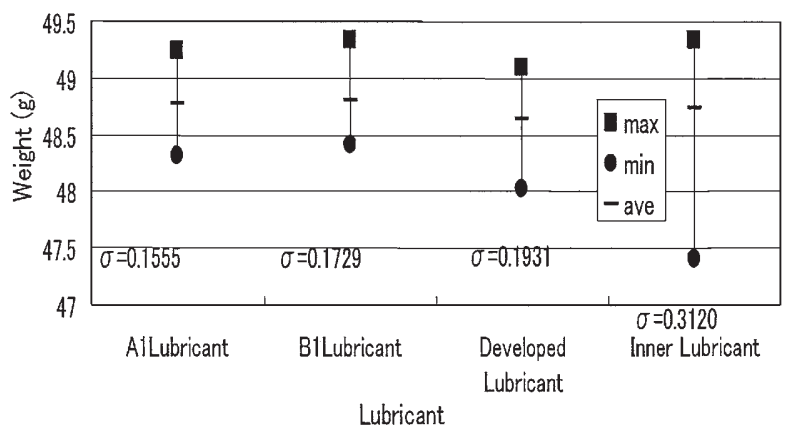

Fig.8 Weight scatter under the several conditions (hockey-pack shape, $n=100$ ).

ように, 開発材による金型潤滑の場合が一番抜き出し圧力が 低くそのバラツキも小さいことが認められる.Fig.8に重量バ ラツキを示す従来法に比べて金型潤滑法はどれもバラツキが 小さい. Fig.9に密度のデータを示す. 全ての方法で $7.3 \mathrm{Mg} / \mathrm{m}^{3}$ を超えているが特に開発潤滑剤によるバラツキは小さい.

\section{5 ま と め}

鉄系焼結材および圧粉軟磁性材の高密度化を目標として金 型潤滑技術について, 定量的な検討を行った結果以下の結論 を得た。

(1) 静電方式では摩擦帯電による方法が装置が小型で自動化 に有利である。

(2) スクリュウコンベアによる潤滑剤の定量切り出し機能が ついた金型潤滑装置が量産には適していることが判った.

(3) ファラデーゲージにより各種材料の電位量を測定でき,こ の值が高い潤滑剤は金型への付着力も高い事が確認できた。

(4) 樹脂系，ワックス系および金属石検等を含む各種の潤滑 剤を比較検討した結果 EBS, 脂肪酸アミド誘導体とステ アリン酸リチウムを溶融混合した新潤滑剂が金型潤滑に もっとも適していることがわかった。

(5) 上記の開発した潤滑剤は量産でも十分利用可能であるこ とが判った。

\section{謝辞}

本開発において成形の試作および金型潤滑装置の導入に対

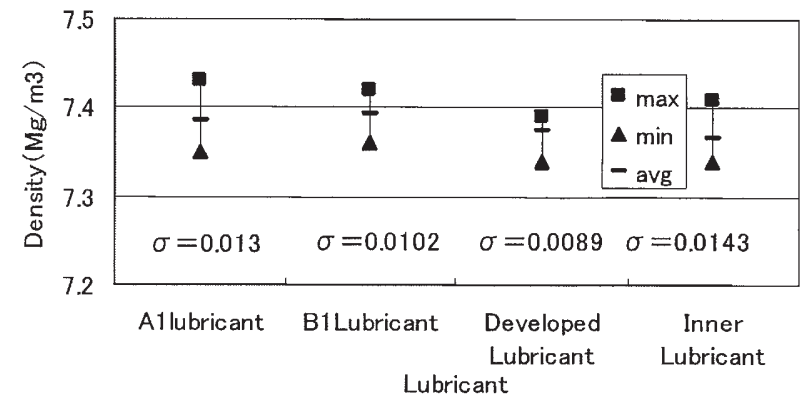

Fig.9 Achieved density under the several conditions (hockey-pack shape, $n=100$ ).

して多大な協力をいただいた侏神戸製鋼の関係各位に感謝い たします。

\section{文献}

1) A.Fujiki, T.Hirao, M.Yamaguchi, T.Murata, K.Ueda and Y.Sugaya: "Development of Warm Compacted Automotive Engine Sprocket", Proceeding of 2000Powder Metallurgy World Congress, Published by Japan Society of Powder and Powder Metallurgy, (2001)137-140.

2) A.Fujiki: "Tough P/M Materials for Automotive Applications", ADVANCES in Powder Metallurgy \& Particulate Materials 2 PM ${ }^{2}$ TEC 2002 WORLD CONGRESS published by MPIF, USA, (2002)31-38.

3) A.Fujiki, Y.Maekawa, Y.Mabuchi, M.Satoh and J.Yamada: "Mechanical Properties of Warm Compacted/Sintered and Surface Densified Sprocket in Comparison Warm Compacted and High temperature Sintered Parts", End user meets PM, Proceeding of PM2004 Viena, Austria, (2004) (to be publshed).

4) W.G.Ball et.al.: "New Die Wall Lubrication System", INTERNATIONAL JOURNAL of Powder Metallurgy Jan/Feb., 33/1 (1997)23-30.

5) M.Kondoh and H.Okajima: "High Density Powder Compaction Using Die Wall Lubrication", Advances in Powder Metallurgy Particulate Materials 3, PM²TEC 2002 WORLD CONGRESS published by MPIF, USA, (2002)47-54. 